\title{
オーステナイトに固溶した窒素の活量におよ淁す コバルト，タングステンの影響
}

\author{
盛 利 貞 ${ }^{*}$ 瀬 英 爾*
}

Toshisada Mori and Eiji Ichise : Effects of Cobalt and Tungsten on the Activity of Nitrogen in Austenite. The solubility of nitrogen in austenite was measured on ironcobalt and iron-tungsten alloys in order to study the effects of alloying elements on the activity of nitrogen and to determine the interaction parameters of nitrogen with alloying elements. The measurements were performed within the austenite range: the experimental temperatures were $1050^{\circ}, 1150^{\circ}$ and $1250^{\circ} \mathrm{C}$ and the percentages of additives were up to ca, $80 \%$ for cobalt and up to $2.5 \%$ for tungsten. Solubility measurements were carried out by a quenching method. The results show that cobalt increases the activity of nitrogen, but tungsten decreases it. The interaction parameters are

$$
\begin{aligned}
\quad=3.89\left(1250^{\circ} \mathrm{C}\right) & =-10.3\left(1250^{\circ} \mathrm{C}\right) \\
\varepsilon_{\mathbb{N}, a}^{(\mathrm{CO})} & \text { and } \varepsilon_{\mathrm{N}, a}^{(\mathrm{W})}=-16.5\left(1150^{\circ} \mathrm{C}\right) \\
=3.98\left(1050^{\circ} \mathrm{C}\right) & =-20.2\left(1050^{\circ} \mathrm{C}\right) .
\end{aligned}
$$

The relationship between interaction parameters and atomic number or temperatures was also discussed.

(Received September 5, 1963)

\section{I. 緒}

著者らはオーステナイト中における窒素の挙動を熱力学 的に把握するための基碟的資料として，オーステナイトに 固溶した窒素の活量およびそれにおよぼす添加元素の影響 饥いて調查している. 添加元素として Cr, Mn, Ni 沉つ いてはすで報告した(1)(2)．本報ではCo扣よびWの影響 について報告する。

\section{II. 実 験 方 法}

合金中に固溶したがスの活量はとの飽和溶解度を測定す ることによつて容易に求められる，著者らは溶解度湘定 の方法として前竍(1)同样, 急冷法を用いた。湘定温度は $1050^{\circ}, 1150^{\circ}, 1250^{\circ} \mathrm{C}$ とし，合金元素の添加量はオーステ ナイト相を形成する範囲とした．Coはこの温度では全率 固溶してオーステナイト相を作るので $82 \%$ をで添加し，W

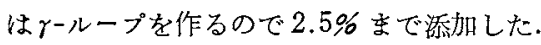

\section{1. 試料の調慗}

試料は高周波加熱真空熔解鋳造怰で熔製して $5 \mathrm{~kg}$ 鋼塊 とし、これを0.1〜0.15 mm 厚さの箔に䤦造圧延した。Co 合金の目標成分は $3,6,12,25,40,50,75 \% \mathrm{Co}, \mathrm{W}$ 合金生 $0.5,1.5,2.5 \% \mathrm{~W}$ とした.

使用した原料純鉄の化学成分几ついては第 1 報(1)に述へ たと扣りである.使用した電解Co は小豆大の水落し品で 純度は $99 \%$ 以上であり，W は粉末を成型，予備焼結した るので純度は $99.99 \%$ でらた。

* 京都大学工学部治金学教室 (Department of Metallurgy, Faculty of Engineering, Kyoto University, Kyoto)

(1) 盛, 新名, 一瀬, 諸岡: 本誌, $27(1963), 49$.

(2) 盛, 新名, 一瀬, 小山：本誌, $27(1963), 53$,
Co 合金鈠造の際， 3 括よび $12 \%$ Co 以外の試料はすへ て割れを生じ王延不能となつたので，上記以外の試料は鋼 塊から旋盤㴔を採取して実験に供した。

\section{2. 実駼装置}

装置の詳細は第 1 報(1)で述べたからここでは省略する。 な郝従来，本研究では試料と平衡させる窒素に】５％の 水素を混入していた，これは試料の窒素吸収を阻害すると いわれる試料表面の酸化被膜の生成を防止するためであっ たが，水素を混合しなくても試料表面に酸化被膜が認めら れず，むしろ水素の共存によつて窒素溶解度が影響を受け る恐れがあるので本実験では水素の混合をとりやめ, 試料 を純窒素と平衡させた．水素の影響についてては別途に発表 の予定である。窒素吸収が平衡に到達するために必要 な加熱保持時間はこの実験条件 (温度 $1050^{\circ} \sim 1250^{\circ} \mathrm{C}$, 試 料の厚さ0.1〜0.15 mm)では純鉄では 10〜20 hrで充分で あること，また各種合金の場合も50hr 以上保持すれば充 分であること(1) (3) が判っているが，本実験では加熱保持 時間を 100〜150 hr とした. 窒化後の急冷に際しては試料 を高温部から抽出し約 $5 \mathrm{sec}$ 以内で赤色が消え， $1 \mathrm{~min}$ 程 度で室温に到達するのでこの間に吸収された窒素が逃げ出 すとしてる無視できるるのと考觉られる。

\section{3. 分 析}

合金中に固溶した窒素の分析は前報と同様に酸分解後, 水蒸気蒸溜ネスラー比色法により行なつた. CoはJIS-G. $1222^{(4)}$ の比色法により分析した. 本実験では試料のCo 含

(3) N.S. Corney \& E. T. Turkdogan : JISI, 180 (1955) , 344.

(4)「鋼拉よび銑鉄のコ バルト分析方法」JIS G.1222 (1958)，日本規格協会，東京. 
有量が 3〜80\% の広範囲にわたることを考慮して標準溶液 による検量線作成 (Co 量 $0.2 \sim 1.2 \mathrm{mg} / 200 \mathrm{cc}$ ) に際して鉄 の共存量を $0.3,2.0,10 \mathrm{mg} / 200 \mathrm{cc}$ と変化させてそれぞれ検 量線を引いたが，鉄の共存量による差はほとんど認められ なかつたので,これらの値を総合して検量線を決定した ${ }^{(5)}$. W はJIS-G.1220(6)の重量法により分析した。な拓標準試 料として日本鉄鋼標準試料十一号 $(2.03 \%$ W)を用いた.

\section{III. 実 験 結 果}

\section{1. $\mathbf{F e}-\mathrm{Co}-\mathrm{N} 3$ 元 系}

$3.35,6.62,12.8,25.3,40.5,54.7,82.0 \% \mathrm{Co}-\mathrm{Fe}$ 合金を $1050^{\circ}$ 扣よび $1250^{\circ} \mathrm{C}$ で $1 \mathrm{~atm}$ の窒素気流と平衡させて得 た窒素飽和溶解度を Fig.1 に示した. Co 含有量の増加と ともに窒素の飽和溶解度は減少している. すなわち Co は オーステナイトに固溶した窒素の活量を増大させる．Co はその化学的性質は Ni と類似しているが, Ni の場合に認 められたような(2), 各温度についての溶解度曲線の交差は 認められなかつた.

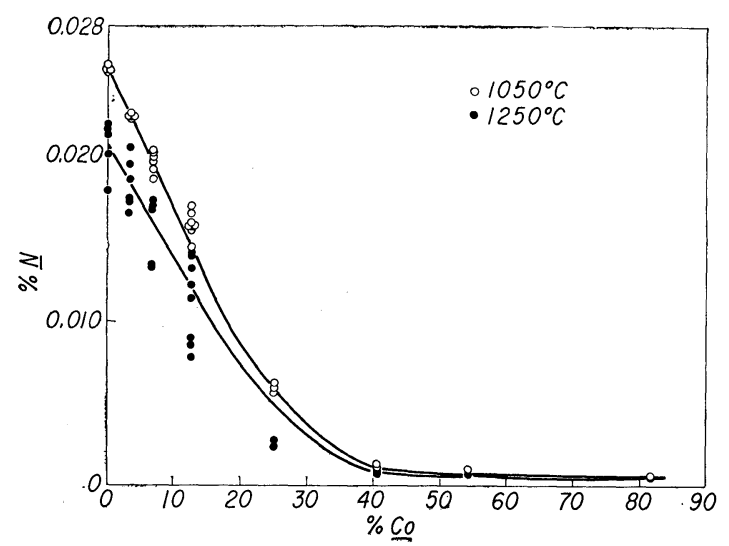

Fig. 1 Solubility of nitrogen in $\mathrm{Fe}-\mathrm{Co}$ alloys $(0 \sim 82 \% \mathrm{Co})$ at 1 -atm pressure of nitrogen.

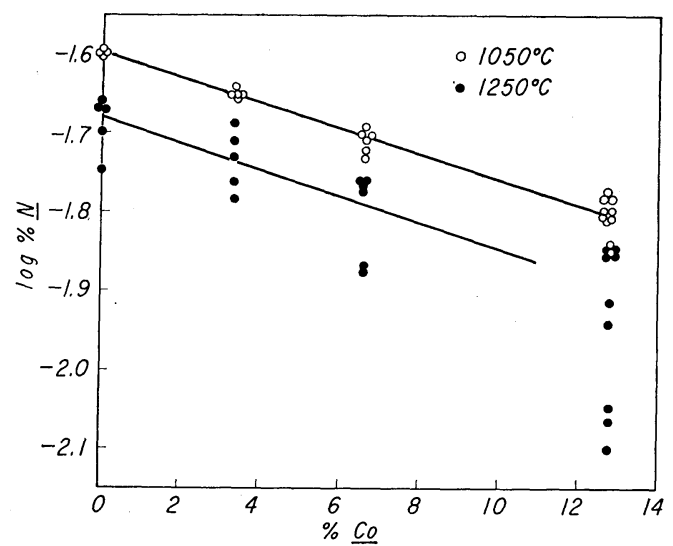

Fig. 2 Solubility of nitrogen in $\mathrm{Fe}-\mathrm{Co}$ alloys $(0 \sim 13 \% \mathrm{Co})$ at 1 -atm pressure of nitrogen.

(5) 水口: 京都大学工学部治金学科特別研究報告, (1963).

（6）「鋼および銑鉄のタングステン分析方法」JIS G. 1220，(1958)，日本規格協会, 東京.
また窒素溶解度の対数と Co 含有量の関係を, 直線関係 のほぼ成立する 12\% Co までの範囲でFig.2 に示した. 最 小自乗法を $6.62 \%$ Co までの範囲に適用して計算すると次 式を得た.

$$
\begin{aligned}
& \log [\% \mathrm{~N}]=-1.6824-0.01624[\% \mathrm{Co}] 1250^{\circ} \mathrm{C}(1) \\
& \log [\% \mathrm{~N}]=-1.5960-0.01661[\% \mathrm{Co}] 1050^{\circ} \mathrm{C}(2)
\end{aligned}
$$

\section{2. $\mathbf{F e}-\mathbf{W}-\mathbf{N} 3$ 元系}

$0.52,1.50,2.53 \% \mathrm{~W}-\mathrm{Fe}$ 合金を $1250^{\circ}, 1150^{\circ}, 1050^{\circ} \mathrm{C}$ で $1 \mathrm{~atm}$ の窒素気流と平衡させて得た窒素飽和溶解度の対数 をFig. 3 に示した.W含有量の増加とともに窒素飽和溶解

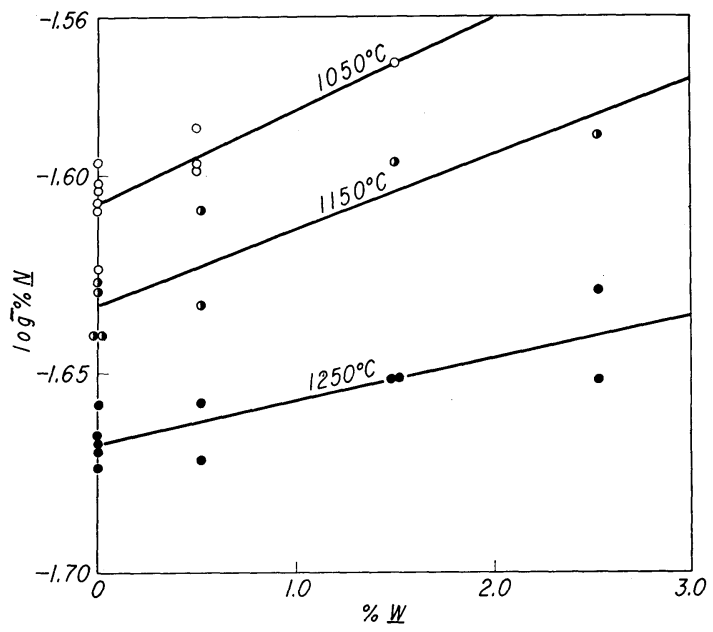

Fig.3 Solubility of nitrogen in Fe-W alloy at 1 -atm pressure of nitrogen.

度も増加している.すなわちWはオーステナイトに固溶し た窒素の活量を低下させる，図に执いて直線が成立するも のとして最小自乗法により次式を得た.

$$
\begin{aligned}
& \log [\% \mathrm{~N}]=-1.6676+0.01058[\% \mathrm{~W}] 1250^{\circ} \mathrm{C}(3) \\
& \log [\% \mathrm{~N}]=-1.6326+0.01885[\% \mathrm{~W}] 1150^{\circ} \mathrm{C}(4) \\
& \log [\% \mathrm{~N}]=-1.6070+0.02356[\% \mathrm{~W}] 1050^{\circ} \mathrm{C}(5)
\end{aligned}
$$

\section{IV. 考察}

本実験は窒素の活量を一定 $\left(\mathrm{P}_{\mathrm{N}_{2}}=1 \mathrm{~atm}\right)$ にしてその飽和 溶解度を測定したのであるから, 活量一定の場合の相互作 用助 (母) 係数を求める.

濃度の単位として重量百分率を用いたときの活量一定の 場合の相互作用助係数 $e_{\mathrm{N}, a}^{(\mathrm{X})}$ 㧊よびモル分率を用いたとき の活量一定の場合の相互作用母係数 $\varepsilon_{\mathrm{N}, a}^{(\mathrm{x})}$ はとれぞれつぎの ように定義される.

相互作用助係数 $e_{\mathrm{N}, a}^{(\mathrm{X})}=\left(\partial \log f_{\mathrm{N}} / \partial[\% \mathrm{X}]\right)_{\boldsymbol{a}_{\mathrm{N}}}{ }^{\prime}$

$$
[\% \mathrm{X}] \rightarrow 0
$$

相互作用母係数 $\quad \varepsilon_{\mathrm{N}, a}^{(\mathrm{X})}=\left(\partial \log \gamma_{\mathrm{N}} / \partial \mathrm{N}_{\underline{\mathrm{X}}}\right)_{a} \underline{\mathrm{N}}$

$$
\mathrm{N}_{\underline{\mathrm{X}}} \rightarrow 0 \text { (7) }
$$

ここで $f_{\mathrm{N}}, \gamma_{\mathrm{N}}$ はそれぞれ Henry 基準执よび Raoult 基準の 活量係数であり，[\% $\mathrm{X}],[\% \mathrm{~N}], \mathrm{N}_{\mathrm{X}}, \mathrm{N}_{\mathrm{N}}$ はそれぞれ 添加元素Xおよび窒素の重量百分率，およびモル分率であ 
る.

$$
\text { さて, } \quad a_{\mathrm{N}}=f_{\mathrm{N}}[\% \mathrm{~N}]
$$

であるから，活鼠一定の相互作用助係数は

$$
e_{\mathrm{N}, a}^{(\mathrm{X})}=\left(\partial \log f_{\mathrm{N}} / \partial \% \underline{\mathrm{X}}\right)_{a_{\mathrm{N}}}=-(\partial \log [\% \underline{\mathrm{N}}] / \partial \% \underline{\mathrm{X}})_{a \underline{\mathrm{N}}}
$$

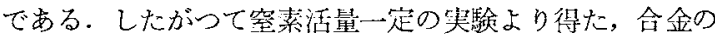
添加元素濃度と空素の溶解度の対数との関係を示す曲線の [\%X] $\rightarrow 0$ K拈ける勾配から，相互作用助係数が求められ

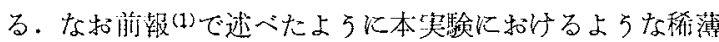
溶液では Henry の法則が成立し，したがつて活量一定に和 ける相互作:用助係数の优は前報(1)(2)で求めた濃度一定に和 兴相互作用助係数 $e_{\mathrm{N}, c}^{(\mathrm{X})}$ の倠と一致する。 また $e_{\mathrm{N}, a}^{(\mathrm{X})}$ と $\varepsilon_{\mathrm{N}, a}^{(\mathrm{X})}$ との間の関係式として Schenck,Frohberg u.Steinmetz(7) が次式を与党ている。すなわち [\% X]， $N_{X} \rightarrow 0$ に対しては

$$
\varepsilon_{\mathrm{N}, a}^{(\mathrm{X})}=\left(2.303 \cdot e_{\mathrm{N}, a}^{(\mathrm{X})}-1\right) \mathrm{M}_{\mathrm{X}} / \mathrm{M}_{\mathrm{Fe}}+1
$$

ここに $\mathrm{M}_{\mathrm{Fe}}, \mathrm{Mx}$ はとれぞれ $\mathrm{Fe}, \mathrm{X}$ の原子量である。

(1) (2) 拈よび (3) 〜 (5) 式に(9) 式を適用して $e_{\mathrm{N}, a}^{(\mathrm{Co})}, e_{\mathrm{N}, a}^{(\mathrm{W})}$, さらに(10) 式により求めた $\varepsilon_{\mathrm{N}, a}^{(\mathrm{CO})}, \varepsilon_{\mathrm{N}, a}^{(\mathrm{W})}$ をTable 1 K示し た。

Table 1 Interaction parameter of nitrogen by cobalt and tungsten.

\begin{tabular}{c|c|c|c}
\hline & $1250^{\circ} \mathrm{C}$ & $1150^{\circ} \mathrm{C}$ & $1050^{\circ} \mathrm{C}$ \\
\hline$e_{\mathrm{N}, a}^{(\mathrm{Co})}$ & 0.0162 & - & 0.0166 \\
$\varepsilon_{\mathrm{N}, a}^{(\mathrm{Co})}$ & 3.89 & - & 3.98 \\
$e_{\mathrm{N}, a}^{(\mathrm{W})}$ & -0.0106 & -0.0188 & -0.0236 \\
$\varepsilon_{\mathrm{N}, a}^{(\mathrm{W})}$ & -10.3 & -16.5 & -20.2 \\
\hline
\end{tabular}

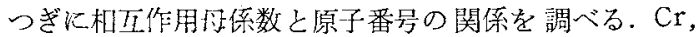
Mn,Ni 亿ついては前被(2)で濃度一定に特ける相互作用旺 係数 $\varepsilon_{\mathrm{N}, c}^{(\mathrm{x})}$ についてその関係を論じたが，本報ではこれらの 元菜沉ついて (10) 式を谪用して $\varepsilon_{\mathrm{N}, a}^{(\mathrm{X})}$ を求め，市らためて Co，W ととるにFig.4亿示した. Fig.4から判るように

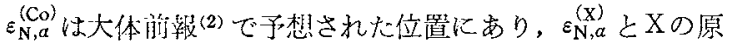

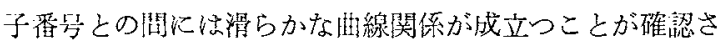
れた.この曲楾の形はPeh1ke \& Elliott(8) やOhtani \& Gockeen(9) あるいは Schenck, Frohberg u. Heinemann

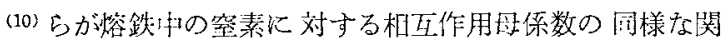
係比与光た形比類似している，W とCr は同属であるから H. Schenck ら (10) によれば $\varepsilon_{\mathrm{N}, a}^{\left(\mathrm{C}_{r}\right)}$ と $\varepsilon_{\mathrm{N}, a}^{(\mathrm{W})}$ は等しいはづであ るが，本”具験結果では $\left|\varepsilon_{\mathrm{N}, a}^{(\mathrm{W})}\right|$ の方が少し小さい。

つぎに相互作用母係数之温度の関倸を淍へる。湔報(2)同 樣，和H，斎藤(11)の提出した次式にしたがつて絶対温度

(7) H. Schenck, M. G. Frohberg u. E. Steinmetz: Arch. Eisenhütt., 31 (1960),671.

(8) R.D.Pehlke \& J.F.Elliott: Trans. Met. Soc. AIME, 218(1960), 1088.

(9) M.Ohtani \& N.A.Gockcen: Trans. Met. Soc. AIME, 218(1960), 533 .

(10) H.Schanck, M.G.Frohberg u. H. Heinemann: Arch. Eisenhütt., 33(1962),593.

(11) 和旺, 斎藤：本誌, $25(1961), 159$.
の逆数に対して $\varepsilon_{N, 2}^{(\mathrm{X})}$ をプロットしたのがFig.5である。

$$
\varepsilon_{\mathrm{N}, a}^{(\mathrm{X})}=\left\{\mathrm{W}_{\mathrm{XN}}-\mathrm{W}_{\mathrm{FeN}}\right\} / R T
$$

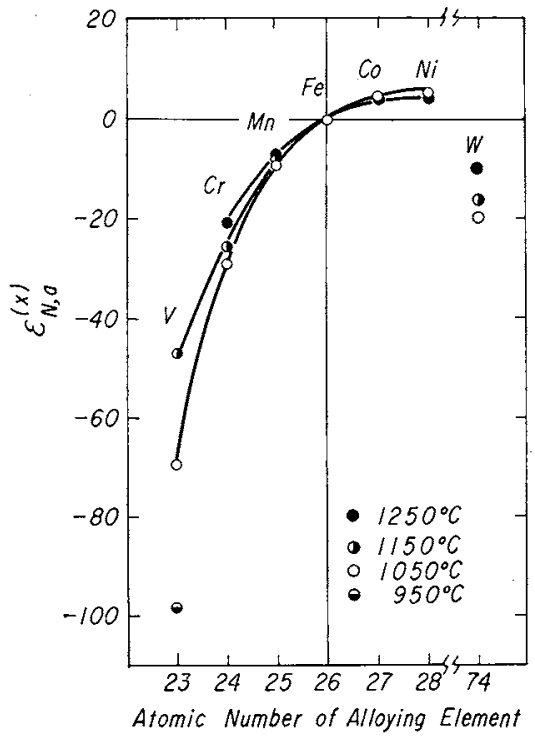

Fig.4 Relationship between interaction parameter and atomic number.

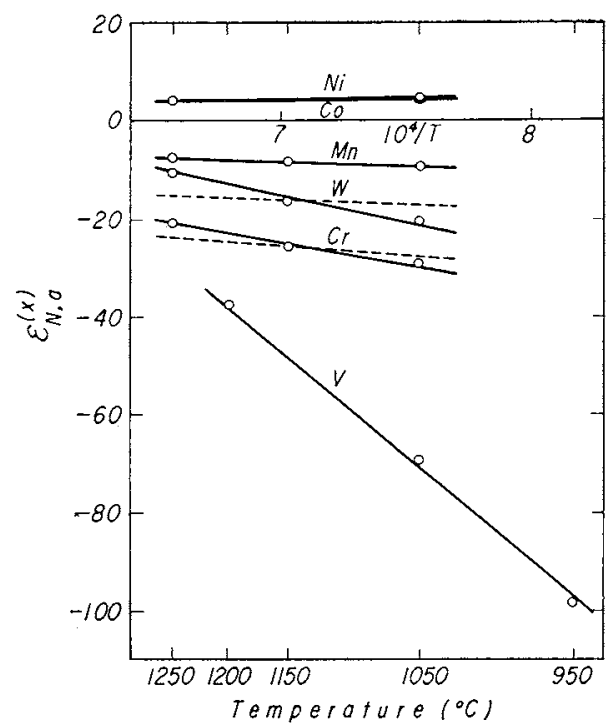

Fig. 5 Relationship between interaction parameter and temperature.

ただしW

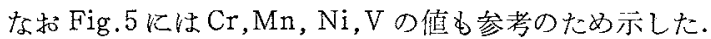
破線は $\mathrm{W}_{\mathrm{XN}}-\mathrm{W}_{\mathrm{FeN}}$ が温度に無関係な場合，すなわち原点

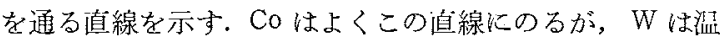
度の影響を大きく受けていることを示す。ここで参考のた めに Pehlke \& Elliott(8)が $1600^{\circ} \mathrm{C}$ の熔鉄についてまと めた相贡作用助係数と比較した(Table 2).

相互作用係数の絶対偡が温度の上算とともに減少するの は(11)式からも明らかであるが，签体ではさらに国体にく らへ原子間距離の堌大や格子の乱れから相互作用が弱くな 
ることが考えられる. Table 2 はこの傾向を判然と示して

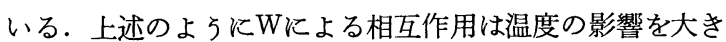

ただし Z 2 は母格子に対する侵入原子の 配位数であり f. c.c.では 6 である.Wの場合はFig. 5 之同様原点を通る直

Table 2 Comparison of the values of $e_{\mathrm{N} \cdot a}^{(\mathrm{X})}\left(\right.$ or $\left.e_{\mathrm{N}, c}^{(\mathrm{X})}\right)$ in liquid iron and in austenite.

\begin{tabular}{|c|c|c|c|c|c|c|c|c|c|c|}
\hline \multirow{2}{*}{ Elements } & \multirow{2}{*}{\multicolumn{3}{|c|}{ Liquid }} & \multirow{2}{*}{\multicolumn{2}{|c|}{ iron at $1600^{\circ} \mathrm{C}^{(8)}$}} & & & \multicolumn{3}{|c|}{ Austenite } \\
\hline & & & & & & & & $1250^{\circ} \mathrm{C}$ & $1150^{\circ} \mathrm{C}$ & $1050^{\circ} \mathrm{C}$ \\
\hline Co & 0.011 & 0.007 & 0.005 & & & & & 0.0162 & - & 0.0166 \\
\hline $\mathrm{Cr}$ & -0.045 & -0.057 & $-0.415^{\dagger}$ & -0.0385 & -0.041 & -0.045 & $-0.38 \S$ & -0.098 & -0.121 & -0.136 \\
\hline $\mathrm{Mn}$ & -0.02 & -0.020 & -0.094 & -0.0245 & & & & -0.034 & -0.037 & -0.041 \\
\hline $\mathrm{Ni}$ & 0.010 & 0.010 & 0.007 & 0.0095 & 0.000 & 0.007 & 0.011 & 0.017 & - & 0.019 \\
\hline $\mathrm{V}$ & -0.010 & -0.11 & -0.105 & & & & & $\left(1200^{\circ} \mathrm{C}\right)$ & $\begin{array}{l}\left(1050^{\circ} \mathrm{C}\right) \\
-0.33\end{array}$ & $\begin{array}{l}\left(950^{\circ} \mathrm{C}\right) \\
-0.47^{*}\end{array}$ \\
\hline $\mathrm{W}$ & -0.002 & & & & & & & -0.0106 & -0.0188 & -0.0236 \\
\hline
\end{tabular}

* Values for vanadium in austenite are refered to the study by R.W.Fountain and J.Chipman(13)

$\dagger$ 斎藤恒三

§ R.M.Brick and A.Creevy の值であるが他の值にくらべてその絶対值が一桁大きく，オーステナイト中の值より む大きくなつている.しかしこれらの原報の曲線の切線より推定すると他の值と同じ桁になるので Pehlke(8) らの 計算の誤りかあるいは䛊植であろうと思われる。

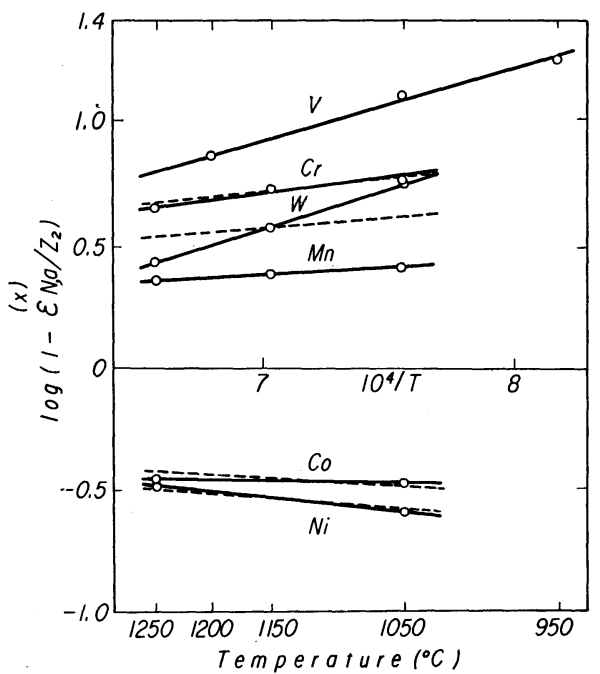

Fig. 6 Relationship between interaction parameter and temperature after Guggenheim's quasichemical equilibrium method.

く受けているが，ここでもW以外の元素については溶鉄中 の相互作用助係数がオーステナイト中のそれの約半分の值 を取るのに対して, Wの場合は $1 / 5 \sim 1 / 10$ と大きく減少し ている.

また八木, 小野(12) の提出したつぎに示す (12) 式にした がつて $\log \left(1=\varepsilon_{\mathrm{N}, a}^{(\mathrm{X})} / \mathrm{Z}_{\mathbf{3}}\right)$ と絶対温度の 逆数との間の関係を Fig. 6 に示した. この場合も破線は原点を通る直線を示し ている.

$$
\left.\log \left(1-\varepsilon_{\mathrm{N}, a}^{(\mathrm{X})} / \mathrm{Z}_{\mathbf{z}}\right)=\mathrm{W}_{\mathrm{FeN}}-\mathrm{W}_{\mathrm{XN}}\right) / \mathrm{Z}_{\mathbf{2}} \cdot 4.575 T
$$

（12）八木，小野：「熔鉄中の炭素の活量およびそれに打 よぼす諸元素の影響について」54 委 615 日本学術 振興会, 製銑第 54 委員会.
線からかなりはずれている。（11) 特よび(12) 式から求めた $\mathrm{W}_{\mathrm{XN}}-\mathrm{W}_{\mathrm{FeN}}$ の值をTable 3 に示した. Co に対する結果 はよく一致しているが，Wについてはかなり異なる值を得 た.いずれの值が妥当であるかについては今後の検討にま たねばならない。

Table 3 Difference of the interchange energy. $(\mathrm{kcal} / \mathrm{mol})$

\begin{tabular}{c|c|c}
\hline Calculated from eq. & $\mathrm{W}_{\mathrm{CoN}}-\mathrm{W}_{\mathrm{FeN}}$ & $\mathrm{W}_{\mathrm{WN}}-\mathrm{W}_{\mathrm{FeN}}$ \\
\hline$(8)$ & 5.2 & 213 \\
$(19)$ & 5.5 & 67 \\
\hline
\end{tabular}

\section{V. 結}

急冷法を用いて Fe-Co 拈よび Fe-W 合金のオーステナ イトの $1 \mathrm{~atm}$ 窒素ガスの飽和溶解度を測定した. その結 果, Co はオーステナイトに固溶した窒素の活量を増大さ せ，Wは逆に減少さすことを確認した. 窒素の活量を一定 にしたときの相互作用助係数拈よび母係数を求め Table 1 に示した. また相互作用母係数を原子番号順にならべると なめらかな曲線を得ることを確かめた(Fig.4). 最後に 相互作用母係数と温度との関係を検討し, interchange energy の差を求めた(Table 3 ).

本研究を行なうにあたり研究費の一部を御援助下さつた 富士製鉄，試料の鍛造圧延を扣引受け下さつた日曹製鋼富 山工場, 大平洋ニッケル新発田工場に深く感謝する. また 実験を行ならにあたり熱心に協力された小山伸二, 水口丈 夫の両氏に謝意を表する.

(13) R.W.Fountain \& J.Chipman: Trans. Met.Soc. AIME, 212(1958), 737 . 